\title{
(息)
}

Citation:

Erickson, KL and Backhouse, SH and Carless, D (2017) Doping In Sports: Do Parents Matter? Sport, Exercise and Performance Psychology, 6 (2). pp. 115-128. ISSN 2157-3913 DOI: https://doi.org/10.1037/spy0000081

Link to Leeds Beckett Repository record:

https://eprints.leedsbeckett.ac.uk/id/eprint/3172/

Document Version:

Article (Accepted Version)

The aim of the Leeds Beckett Repository is to provide open access to our research, as required by funder policies and permitted by publishers and copyright law.

The Leeds Beckett repository holds a wide range of publications, each of which has been checked for copyright and the relevant embargo period has been applied by the Research Services team.

We operate on a standard take-down policy. If you are the author or publisher of an output and you would like it removed from the repository, please contact us and we will investigate on a case-by-case basis.

Each thesis in the repository has been cleared where necessary by the author for third party copyright. If you would like a thesis to be removed from the repository or believe there is an issue with copyright, please contact us on openaccess@leedsbeckett.ac.uk and we will investigate on a case-by-case basis. 
Running head: DOPING IN SPORT: DO PARENTS MATTER?

Doping In Sport: Do Parents Matter? 


\section{DOPING IN SPORT: DO PARENTS MATTER?}

\section{Introduction}

Athletes exist in an environment of complex networks and relationships (Pappa \& Kennedy, 2012; Thomas, Dunn, Swift, \& Burns, 2011). Accordingly, an array of interpersonal, intrapersonal, social, and environmental factors interact systematically (Brown, 2001) to affect doping behavior (Johnson, Sacks \& Edmonds, 2010). That said, anti-doping policies and efforts have traditionally focused on individual athletes, while seemingly disregarding the impact of the people and environment(s) surrounding them. However, recent events in sport - particularly within track and field (e.g., the publication of the Independent Commission Report \#1) - have reiterated the conclusions of the Dubin (1990) report regarding the significant influence of athlete support personnel (ASP) in relation to athletes' doping behaviors. As a result, the importance of targeting athletes' social networks with preventive messages and efforts is underscored and further substantiated in numerous autobiographies from sanctioned athletes (e.g., Dwain Chambers). Moreover, athletes themselves have argued for the importance of punishment extending to those complicit in promoting or facilitating doping (Engelberg, Moston, \& Skinner, 2015).

Stemming from the wider sporting community's evolving appreciation of the fact that athletes generally do not live in isolation (Dunn \& Thomas, 2012), the revised World AntiDoping Agency (WADA) Code (WADA, 2015) now includes increased punishments for ASP associated with doping activity. Importantly, the WADA defines ASP as "any coach, trainer, manager, agent, team staff, official, medical, paramedical personnel, parent or any other Person working with, treating or assisting an Athlete participating in or preparing for sport Competition" (WADA, 2015, p. 132). Given the breadth of this list, there is an urgent need to determine the relevance and influence of particular ASP for shaping athletes' doping attitudes and behaviors. That said, it is recognized that relationships with key individuals in athletes' lives influence their life values and philosophies, and specific persons are related to 


\section{DOPING IN SPORT: DO PARENTS MATTER?}

particular stages in athletes' careers (Storm, Henriksen, Larsen, \& Christensen, 2014). As such, particularly influential members of an athlete's support network commonly evolve alongside an athlete's career progression. To date, research exploring the influence of ASP in the context of doping has predominantly targeted team medical staff and coaches (Backhouse, Whitaker, Patterson, Erickson, \& McKenna, 2015). Meanwhile, among adolescent and young adult athlete populations, coaches and parents have been identified as particularly influential for athletes' doping attitudes, experiences and behaviors. Despite this recognition, research exploring the potential influence of parents in the context of sport doping is sparse (Blank et al., 2013).

Within the broader social sciences, parents have been identified for their protective function by offering adolescents a secure base (Hair, Moore, Garrett, Ling, \& Cleveland, 2008). Close relationships with parents have also been found to protect adolescents against:

a) deviant peer groups and subsequent delinquency (Fergusson, Vitaro, Wanner, \& Brendgen, 2007), b) offending and re-offending (Rennie \& Dolan, 2010), and c) smoking behaviors (Mercken, Sleddens, de Vries, \& Steglich, 2013). Within the doping literature, parents were recognized as one of the most likely groups to lead adolescents towards doping more than a decade ago (Laure \& Binsinger, 2005) and it has been noted that parental pressure to be perfect (Madigan, Stoeber, \& Passfield, 2016) and towards winning (Chan et al., 2014) may lead athletes to consider using performance enhancing drugs (PEDs) in some cases. Furthermore, when adolescent athletes believed significant others in their lives would approve of PED use, they were more likely to use doping substances (Lucidi, Zelli, Mallia, Grano, Russo \& Violani, 2008; Zelli, Mallia \& Lucidi, 2010). Conversely, Erickson, McKenna and Backhouse (2015) highlighted the potential for parents to discourage the use of PEDs among young adult athlete populations. The possibility appears to be further enhanced when athletes believe that using PEDs would reflect poorly on significant others (e.g., 


\section{DOPING IN SPORT: DO PARENTS MATTER?}

parents) in their lives (Chan et al., 2014; Dimeo, Allen, Taylor, Dixon, \& Robinson, 2012). Accordingly, it seems parents have the potential to influence athletes' doping attitudes and behaviors; meanwhile, the direction of influence can vary depending on parenting styles. With that in mind, this study sought to contribute to the psychology of doping in sport by exploring: 1) the experiences of British track and field student-athletes in relation to their attitudes, experiences and behaviors towards doping in sport, and 2) the (potential) influence of significant others in shaping these.

\section{Method}

\section{Philosophical Underpinnings}

Working within the interpretive paradigm, this research adopted relativist ontology (reality is socially and experientially influenced and shaped) and transactional/subjectivist epistemology (the investigator and investigated are linked through their interactions and findings form as the investigation unfolds).

\section{Participants and Procedures}

The study focused on the experiences of 'student-athletes' - individuals who were undertaking (or completed within the past year) university-level education. Within the UK, athletes are not required to continue with higher education; thus, they are permitted to pursue elite athletic careers as they choose. Despite this, the number of elite athletes pursuing higher education continues to increase (Aquilina, 2013) and new initiatives (e.g., Talented Athlete Scholarship Scheme) have been established to help facilitate this evolution. British Universities and Colleges Sport (BUCS) - the national governing body for higher education sport in the UK - is designed to enhance the student experience through sport and includes nearly 170 universities/colleges and over 4800 teams (BUCS, 2016). However, it is important 


\section{DOPING IN SPORT: DO PARENTS MATTER?}

to note that within the sport of track and field, high performing (i.e., international standard) British student-athletes generally train with external coaches - distinct from university coach(es) - and remain isolated from the broader university athletics team. Additionally, they predominantly compete separate from the university throughout their student-athlete careers and instead, represent their outside clubs and affiliations in competition.

Student-athletes were an important group to target for this research due to their susceptibility to doping (Erickson, McKenna \& Backhouse, 2015); they are considered to be at elevated risk for PED use (Buckman, Farris, \& Yusko, 2013; Yusko, Buckman, White, \& Pandina, 2008) and represent one of the most doping-influenced populations (Zenic, Stipic, \& Sekulic, 2013). Meanwhile, across all sports, track and field athletes have the highest risk of doping (Alaranta et al., 2006; Pappa \& Kennedy, 2012). Furthermore, research (Pappa \& Kennedy, 2012) suggests the period from 19-26 years of age represents the prime years of track and field athletes' competitive careers (Yesalis, 2000). Taken together, track and field student-athletes represent an ideal target group for doping research.

Following ethical approval from the host institution, snowball sampling was employed to identify suitably information-rich participants. This involved multiple approaches, including utilizing the researchers' networks and the connections of participants already interviewed (McNamee, 2012). The reassurance provided by interviewed participants helped to attract further participants who were potentially reluctant to discuss such a taboo topic (Bloodworth, Petróczi, Bailey, Pearce \& McNamee, 2012). Additionally, identified members of the community (e.g., coaches, colleagues) further identified other members and an invitation to participate in the study was offered (Fink, 1995). Participants were included based on the following criteria: 1) undergoing (or have completed within the past year) university level education, 2) compete in the sport of track and field, and 3) minimum second year student-athletes at university in order to increase their exposure to the university student- 


\section{DOPING IN SPORT: DO PARENTS MATTER?}

athlete environment. Participants were not required to have (or not have) experience with and/or exposure to PEDs. In total, 14 British student-athletes $(\mathrm{M}=8, \mathrm{~F}=6)$ agreed to participate. Consistent with Mazanov, Hemphill, Connor, Quirk and Backhouse (2015, p. 221), our aim "was to find coherent explanations of the data rather than achieve consensus". Ensuing from the data analysis running alongside the data collection, recruitment stopped at this point as salient themes were emerging from within the rich data. Participants ranged in age from 19 to 26 years old $(\mathrm{M}=21.07, \mathrm{SD}=2.06)$ and were recruited from geographically diverse universities across the UK. They represented various track and field events and had experience in international $(\mathrm{N}=10)$, national $(\mathrm{N}=1)$, and regional $(\mathrm{N}=3)$ competitions.

Responding to calls (e.g., Hoff, 2012) for a more dynamic methodological approach within doping literature, our research adopted a narrative approach. Narrative research assumes that individuals' lives are storied and that the self is narratively constructed. Individuals organize their experiences through and into narratives, and assign meaning to them through storytelling (Phoenix, Smith, \& Sparkes, 2010). Accordingly, narrative research focuses on the stories that people tell about their experiences (Sparkes \& Smith, 2014), taking into consideration how these stories unfold over time (Smith, 2010). In line with this approach, data was collected using semi-structured interviews, allowing for flexibility according to what the participants shared. Interviews were conducted face-to-face by the lead author at various locations throughout the UK (as chosen by participants) and ranged in length from 50 minutes to nearly three hours $(M=1$ hour 45 minutes). All interviews were audio-recorded as agreed by participants.

The interview approach sought to gather participants' life stories. Although the term 'story' and 'narrative' are often used interchangeably, for this research we have adopted Douglas and Carless's (2015) approach (based on Frank, 1995), considering a 'story' specifically to be an account told by a particular person about events and happenings in his 


\section{DOPING IN SPORT: DO PARENTS MATTER?}

life throughout. Gathering life stories traditionally involves repeat interviews, however, as Plummer (2001) notes, short life story interviews can also be usefully employed, particularly if a specific focus is appropriate (e.g., Carless \& Douglas, 2013). This is the approach we took. Accordingly, participants were encouraged to provide an account of their athletic career, with childhood and early experiences serving as the catalyst for key stages and experiences in their adult sporting career (Sparkes \& Smith, 2009). Congruent with a life story approach, and given the sensitive and stigmatized nature of doping in sport, interviews commenced with a focus on individuals' athletic careers rather than directly addressing doping. To illustrate, the first question asked was: can you describe how you first became involved in sport? Questions then progressed to where they are now (e.g., describe for me the progression of your athletic career?), and culminated with a discussion of their views towards doping in sport (e.g., Focusing on performance enhancing strategies (PES), can you recall having previous conversations about performance enhancing substances with other individuals? Describe one of those conversations for me). When discussing the progression of their careers, participants were prompted to discuss key relationships throughout their careers (e.g., tell me about your parents? I'm curious as to what kinds of coaches you have had? What have relationships with teammates looked like?). The overall structure of the interview guide was considered significant in light of other researchers (Douglas \& Carless, 2015) warning that a rich understanding of emotions, responses and meanings is not possible without an appreciation for what has gone before and what is expected to come after. Accordingly, once the interview guide was developed it was reviewed by researchers experienced in qualitative research. 


\section{DOPING IN SPORT: DO PARENTS MATTER?}

\section{Data Analysis}

As is often the case with qualitative research, data collection and analysis more commonly happened simultaneously rather than sequentially. Due to a lapse in interviews, the data was analyzed in two separate waves following a hybrid approach (Fereday \& MuirCochrane, 2006) based upon the thematic analysis described by Braun and Clarke (2006). The first dataset encompassed a preliminary 10 interviews, which were transcribed verbatim by the lead author (i.e., interviewer) and managed using Olympus Sonority software. In order to develop themes and concepts, transcripts were read multiple times to become familiar with the data (Douglas \& Carless, 2009). Following an inductive analysis approach, initial codes for the data were created and then sorted into potential themes. Once initial themes were established, a thematic map displaying the various themes was created and discussed among the research team, with amendments made accordingly. This process allowed for themes to be further scrutinized and determined whether or not they appropriately depicted what was present in the data. Deliberations between the lead author and research team were also considered important for minimizing position bias throughout the analysis process. A detailed analysis for each unique theme was carried out to ensure that there was adequate narrative support for each, and themes were considered both individually, as well as in relation to one another.

Following this, four further individuals meeting the inclusion criteria were identified and as a research team, it was decided to include them in the research. Accordingly, four additional interviews were conducted by the lead author in an effort to elaborate and crystallize emerging interpretations. Employing the same transcription process, a deductive analysis was carried out on the supplementary transcripts. Specifically, each of the four transcripts was individually mapped against the themes that emerged in the initial inductive analysis. This process allowed for working propositions to be developed and verified. 


\section{DOPING IN SPORT: DO PARENTS MATTER?}

Similar themes materialized from within this second wave of analysis, suggesting that the themes were reasonably consistent. Therefore, the final results and discussion are based on the combination of all 14 interviews. Throughout, pseudonyms have been used and the specific track and field event removed to protect participant anonymity.

\section{Markers of Quality}

Judging the quality of quantitative research is generally straightforward, revolving around issues of objectivity, reliability, generalizability, and validity (Sparkes \& Smith, 2014). In contrast, readers of qualitative studies are required to assess the quality of the research in the absence of universally accepted criteria. Consequently, some readers may appreciate guidance concerning how to judge this study. Several criteria are offered by Morse (2012) as ways to assess whether a qualitative study is high quality. While targeted at health research, we find her flexible and practical suggestions to be useful and appropriate to our study given its philosophical underpinnings. First, does the study contribute new insights? Do the findings surprise the reader? Second, is enough data presented for the findings and interpretations to be convincing? Third, does the reader gain the impression the authors are confident of their claims? Fourth, are the new findings clear, exciting and profound? Finally, do the findings make sense to the reader? Does the reader see how they could be useful?

\section{Findings}

When discussing the influence of significant others in participants' lives, references to parents and the substantial influence they have had on these student-athletes, beginning at an early age and continuing to the present day, were prominent. Accordingly, the following themes were identified with regards to how parents have influenced athletes' current attitudes, experiences and behaviors towards doping in sport: 1) "Right from wrong", 2) 


\section{DOPING IN SPORT: DO PARENTS MATTER?}

"Biggest support, parents, without a doubt", and 3) "Pay respect". In the following sections, each theme is presented in detail.

\section{"Right from wrong"}

Researchers (e.g., Collins, MacNamara, Collins, \& Bailey, 2012; Erickson et al., 2015; Morente-Sánchez, Mateo-March, \& Zabala, 2013) have previously demonstrated the influence of personal morals for PED decision-making, and there is an increasing argument that morality should be integrated into anti-doping interventions (e.g., Overbye, Elba, Knudsen \& Pfister, 2015). Yet, limited research has attempted to identify when and/or how personal morals are established, and even less has considered how they (may) evolve over time. Insightfully, our research highlights parents as being influential in both instances: 1) informing athletes' initial sense of right and wrong, and 2) the evolution of athletes' personal morals over time.

Looking first at the role of parents for establishing athletes' personal morals; upon reflection, Bob shared that he had, "quite strict parents as a youngster like they did sort me out...right from wrong pretty quickly". Consequently, he specified that in relation to his attitude towards PEDs, “yeah I think that's probably...helped the fact that I've been taught definitely what was right and what was wrong from the start”. It appears Bob's parents have been influential in establishing his moral compass. Furthermore, he seems to have adopted his parents' morals as his own and decided to maintain them. Having now left home to attend university, he currently chooses to live by the standards they established rather than feeling obligated to as a consequence of living under their roof. Interestingly, adopting parents' values has been identified as a protective factor against binge drinking in adolescents (Piko \& Kovacs, 2010). 


\section{DOPING IN SPORT: DO PARENTS MATTER?}

Similar to Bob, it seems Mark has also retained the morals that his mum instilled, "the moral factors of... what I've grown up with...like my mum pressuring me to...do it on your own you know and then almost like there's the guilt side of it". Stemming from his mum constantly encouraging him to do things on his own accord, he now assumes that using PEDs would contradict these morals, which he anticipates feeling guilty for. Extending this, Susan mentioned that she feels deterred from using PEDs because, "I think it's just being polite...that's where it started just like make sure you shake the judge's hand after...a competition and just say thank you and...remember your manners like that's been drilled in...obviously by parents". Maintaining the value of practicing 'manners' within sport was established alongside Susan's earliest encounters with sport, and has remained with her. The habitual nature of this apparently serves to deter Susan from PEDs, which she attributes to her parents' influence.

Jane provided an interesting, albeit indirect, example of how using PEDs is associated with her upbringing. Alluding to her childhood, she mentioned that she would be scared of getting caught using PEDs:

Because that's when you like screwed up isn't it? It's like when you were a kid and you did something like it was fine until you get caught but then like you get told off and your parents are disappointed in you.

The fear of disappointing her parents if she 'screwed up' and used PEDs influences Jane's current attitude and behavior towards doping. Corroborating other research (e.g., Chan et al., 2014; Dimeo et al., 2012), Jane is deterred from using PEDs based on her assumption that using them would be viewed negatively by her parents. 


\section{DOPING IN SPORT: DO PARENTS MATTER?}

In addition to shaping participants' initial sense of right and wrong, the transcripts also demonstrate that parents have influenced the development of student-athletes' personal morals over time. Thus, exploring the different types of relationships these student-athletes have with their parents, along with how they have (or have not) evolved, is important.

\section{"Biggest support, parents, without a doubt"}

Participants generally described their parents as providing constant encouragement in and beyond sport. Numerous athletes spoke of their parents sacrificing for them and helping to establish their athletic careers. When asked how they did this, participants provided specific, tangible examples. For instance, Pat mentioned that:

I don't like traveling like I can't manage it with my anxiety disorder I hate traveling...literally like airplanes are the worst thing ever. I had an international competition in 2010 ...trying to get me on that plane was the worst thing ever honestly...my mum and dad weren't going to come...but because I was flying they were like 'ok right we'll get on the same plane' like other people's parents didn't go but mine did.

Pat's parents were aware of his anxiety and recognized that they could do something to reduce it. Noticeably, Pat indicates that this went above and beyond what most parents would do and appreciates their devotion. Echoing this, Mark shared that his mum and sister attended:

Every competition every match... every training session they would be there to watch... or you know be there with either some food...you know to keep me going 


\section{DOPING IN SPORT: DO PARENTS MATTER?}

through the training sessions or the competitions like they never missed one...one competition that there was...over seasons I average about 60 races in a season and...they've never missed one.

Intriguingly, Mark specifies the volume of events this encompassed, potentially indicating his appreciation for the level of commitment exhibited. Meanwhile, his recent transfer to a different sport has limited their ability to attend as most training camps and competitions are done abroad. His previous routine was, "I've got set things I do from the minute I wake up on a competition day - even the conversation with my mum - it's the same sort of conversation every time..." However, now, "on a tour to Europe...that doesn't take place so it's like I'm having to find new ways...” During the interview Mark was visibly distraught over the absence of his family due to logistics. In his own words, their absence has resulted in him, "having to find like a new self pretty much because they can't always be there". It seems Mark's family is enmeshed in his career and this is pivotal to his experiences. Importantly, multiple athletes expressed a sense of appreciation for their parents' commitment.

Susan mentioned that, "I owe them a lot...they're my mini bus basically...took me everywhere and anywhere...kind of like a massive support system and obviously I definitely wouldn't be where I am now without them so...I owe them massively and I know that". Susan suggests that she wouldn't have her athletics career without her parents. They helped her in the past and are equally interested in her current career. This resonates with Brad, as he shared that his parents have, "given me a huge amount of support... I couldn't have done it without them. It wouldn't have happened; it would have been impossible". Brad assumes he would not be where he is now without the key contributions of his parents and appears conscious of the fact that his career has not been established on his own accord. Reiterating 


\section{DOPING IN SPORT: DO PARENTS MATTER?}

Brad's reference to 'support', Ralph specified that, "biggest support, parents, without a doubt. I mean they'd do anything for me". Ralph's parents represent the support network that he relied on growing up, and they remain equally as significant to his current career. This corroborates the findings of Aquilina (2013) who noted that European student-athletes conceded that they were not solely responsible for their academic and athletic success, rather, they depended on their support networks to help them meet the demands of their dual-careers. For nearly all of our participants, parents appear to serve as the key group within their unique support networks.

In particular, parents have guided participants' decision-making. Within our sample, parents regularly advised athletes on choices related to their sport careers, which is consistent with previous work in doping (Smith et al., 2010) and sport development (Lenskyi, 2003). Insightfully, these decisions have had long-term implications for some of the athletes. For instance, Brad shared:

When I started to show a little bit of promise in athletics...parents both kind of said they want me to go and train a bit more regularly...they maybe saw my potential in it before I did. I was kind of like 'ah I'll just play football on the weekends' and that was it; I was fine with that, I enjoyed that...I wouldn't necessarily say I particularly wanted to initially... because I thought 'I'm enjoying football, I'm enjoying what I've got now, why change that? Why...try something else like you may not be particularly good at?' But turns out, I was. And if they hadn't have pushed me...it probably wouldn't have happened, I wouldn't have made the change.

Brad's parents essentially recognized his potential in the sport before he did, and encouraged him into it. Importantly, they never pressured him towards doing the sport or 


\section{DOPING IN SPORT: DO PARENTS MATTER?}

suggested that he should do it because he would likely be more successful with it. Notably, Sally's parents apply a similar approach towards her career, "they're not like pushy...make me do sport. Everything's my choice but like they support my decision in anything I do". Likewise, Pam stressed the value of her parents' approach to her career:

My parents just being completely passive and although they know what I need to do, say 'we love you and you're amazing because you're doing this thing that you want to do but whatever you want to do, it would be amazing if you pursued that'.

Pam suggests that her parents are proud of her career and success; however, she appears confident that this would be the case regardless of what she chose to pursue. Knowing this has resulted in her feeling free to pursue her athletic goals without any pressure or expectations from her parents. Similar sentiments were also expressed by another participant, Pat. In general, participants in this research suggested that their parents actively support their athletic careers, but they do not have expectations for the level of success they should achieve. This is a particularly timely finding in light of Madigan, Stoeber and Passfield's (2016) recent conclusion that within a sample of adolescent British male athletes, perceived parental pressure to be perfect was a vulnerability factor for banned substance use.

Parents commonly served in a logistical role early on in athletes' careers but their involvement has evolved with time. Regarding the roles of parents in athletes' current careers, many participants mentioned that their parents have now shifted into more of a fan club. Parents' assistance in meeting the trivial requirements associated with being an athlete is no longer necessary, but they are still involved. Illustrating this, Paul shared that, "they're now just the fan club they really are and they will come...to as many races as they can". Similarly, despite not living at home anymore, Pat mentioned, "my dad's ringing me every 


\section{DOPING IN SPORT: DO PARENTS MATTER?}

night when he's coming home from work like 'ah how is training going?' and stuff like that so they're still interested in wondering how I'm getting on and stuff'. Bob also expressed an appreciation for having his dad involved in his present career, "I like to talk to him about how I've done and other bits". Despite parents' involvement changing naturally as participants have matured and become more independent, they are still a part of the athletes' careers. Interestingly, American student-athletes have previously reported that family contributes at least as much to their performance as their coaches and teammates (Donohue, Miller, Crammer, Cross, \& Covassin, 2007). Given the significance of parents' contributions to the British student-athletes' careers illuminated here, further research in this area is warranted.

Establishing a strong relationship with parents early in life has resulted in enduring connections for most of the athletes represented here. This is consistent with research in the broader social sciences suggesting that regardless of decreased interactions, family bonds continue to protect adolescents against substance abuse (Field, Diego, \& Sanders, 2002). According to attachment theory (Bowlby, 1969; Bowlby, 1977), these relationships have endured over time and space as a result of their consistency from inception. Exemplifying such a bond, despite no longer living at home, Mark shared, "I barely go a few days without talking to her [mum]". Likewise, Pam said, "me and my mum are so close. Like chatting to her; I always at the end of every day more or less like fill her in on everything I've been doing and stuff'. Similar behavior was mentioned by Richard, Paul and Jane. Insightfully, Sally provided an example of what conversations with her parents are generally about:

Even events in school, football, athletics, friendships, they've always got a say in...if I have anything - any problems - I ring them up like if I don't know how to cook something I ring them up or whatever. I know they're only a phone call away...I don't 


\section{DOPING IN SPORT: DO PARENTS MATTER?}

have to go longer than two weeks' kind of without seeing them. We're always on the phone with each other.

Sally appears comforted by the fact that her parents are 'only a phone call away', which was echoed by Susan, "my mum and dad...just like ringing them up...and just be like 'look this has happened... what do you think I should do? Do you think it's fair that that's happened?' kind of and then just talking it through with them". Continuing to discuss problems with parents is significant in light of substance abuse research stating that maintaining open communication with family members, and in particular, talking about problems with parents, lowers the likelihood of adolescents using substances and drugs in general (Resnick, Bearman, Blum, \& et al., 1997; Stronski, Ireland, Michaud, Narring, \& Resnick, 2000).

Mark and Ralph suggested that their parents' on-going involvement in their lives offers them a (protective) level of supervision. They speculated about how different things would be without their parents' constant involvement and presence in their lives. For Ralph, "I think without them I would be stuck half the time...I would be concerned what I'd do". He also mentioned that, "they know you more than anybody else does", which seemingly leads him to seek their guidance. If that option were ever removed, he appears genuinely concerned about the impact it could have on his daily life, both in and out of sport. Similarly, Mark noted that:

My mum and my sister if they were with me... when I was younger I would have no chance...I'd be slapped stupid before I could actually take them [PEDs]...everybody else around me so far has...had a big influence on me, have been anti-drugs. So...my whole attitude has been anti-drugs so...I haven't had a problem really with going out to search for it or saying 'no' to it...but I feel like...I'd be tempted. 


\section{DOPING IN SPORT: DO PARENTS MATTER?}

Mark's suggestion of now feeling he would be tempted to use PEDs was made in reference to the fact that he no longer lives at home. He explicitly states that prior to leaving home, PEDs were completely off limits and something he had never considered. However, having now been out of the family home for several years, he is intrigued by their potential for bringing him success. He believes that if his mum was still a continuous physical presence in his life then this interest would not have arisen. Going back to the notion of 'right and wrong' and considering that Mark said his mum instilled this in him, the validity of morality as a deterrent to doping is questioned. However, rather than disproving its potential as a deterrent, Mark's situation perhaps reiterates the importance of athletes developing their own moral position, as opposed to simply subscribing to their parents' morals while 'under their roof

Both Ralph and Mark suggest that their parents play a critical role in helping them make decisions. For Mark, the physical presence of his mum is considered significant. Now living away from home, he has become aware of his increased freedom and the implications it could have for him. Meanwhile, Ralph does not necessarily require his parents' physical presence, but both excerpts raise some serious issues. Prominently, university student-athletes are most often not living at home for the first time. Therefore, they have increased freedom resulting from a decreased level of (consistent) adult supervision. In relation, Kindlundh, Isacson, Berglund and Nyberg (1999) suggest that living alone can be considered a distal factor of importance in explaining doping agent onset. Meanwhile, Ohl, Fincoeur, LentillonKaestner, Defrance and Brissonneau (2013) demonstrated that an athlete's position against doping weakens as adult supervision decreases; among professional cyclists, a lack of favorable supervision was one of the most important risk factors for doping use. The new living situation and ensuing lack of supervision are compounded by the fact that not all 


\section{DOPING IN SPORT: DO PARENTS MATTER?}

individuals are raised by adults adhering to pro-social values. Consequently, some individuals likely leave home and start university without a well-established moral compass; certainly not one that has been internalized. The likelihood of resisting temptation in a new environment under these conditions is feasibly jeopardized.

\section{"Pay respect"}

Stemming from the consistent support and involvement provided by parents, participants' stories regularly demonstrated a desire to give back to their parents and assure them that their time and effort is not spent in vain. It seems this aspiration influences their drive for career success and ultimately, their success expresses gratitude towards their parents. Exemplifying this, Ralph shared that:

I think its people...like your family and things like in your mind-set your training and stuff like on a hard day you'd be like 'ah why am I doing this?' and you think 'well it's for them as well' kind of thing. You want them to be proud of you so there's always a bit - they always like set me goals and stuff.

Ralph is conscious of how much his significant others can benefit from his success and views his career as more than just a reflection of his own effort; others are enmeshed in his career and his success is in part due to their efforts. This appears to encourage and guide him. Moreover, this awareness serves as motivation for him to stay committed. Paul echoed this sentiment, "they're [parents] recognizing my commitment... and that kind of reinforces everything that I'm doing". For Bob, the desire to give back to his dad is very personal: 


\section{DOPING IN SPORT: DO PARENTS MATTER?}

My dad had cancer first year I came to Uni...so I wanted to push training for him to try and show that he hadn't wasted... his time like coming to put me through all the training and coming to races. So I wanted to... do a bit for him...I think he knows that...I try and I've always tried like he can tell when I've put in the hard work...yeah probably the first one...to know when I've been working hard and pleased with me.

At the time of his dad's diagnosis, Bob determined that working hard at sport was something within his control and could be used to serve his dad. He does not suggest that winning was his objective; rather, his dad would appreciate his hard work. Consistent with Douglas and Carless (2006), the support of participants' parents was not contingent on their 'success'. In fact, no athlete said their parents promoted success as a priority. Although participants generally want to give back to their parents, they do not endorse the mentality that the only way to do this is by winning or being the best. Instead, working hard and giving their best effort day in and day out will bring their parents the greatest happiness. This is a particularly timely finding considering Chan et al.'s (2014) suggestion that parental pressure towards winning may force athletes to consider using PEDs.

Extending the implications of this mentality, Brad indicated that achieving success would be, "almost as a reward for him [dad] because if I ultimately perform well, a lot of the work and effort's put in by him". Brad is in a unique situation with his dad serving as his current coach. Thus, he maintains the belief that if he is successful it reflects equally on his dad. Since his dad cannot go out and achieve personal success, Brad apparently feels obligated to do it for the both of them. Notably, Brad does not feel pressured to do this; his dad does not expect success from him. Rather, Brad perceives it as something he has control over and can use as a means to give back to his dad. Importantly, Brad defines success as, "if 


\section{DOPING IN SPORT: DO PARENTS MATTER?}

I'm happy with my performance... in myself, then I'd say it was a success". At no point did he suggest success required winning or placing on the podium.

A critical by-product of the longing to make parents proud is that among this group, parents simultaneously serve as motivation to stay away from PEDs. Illustrating this, Richard shared:

To get there [success] I would want to make sure I did a certain - clean - and did it in a way that was respectful to like my family and myself and those who'd sort of been there and around for me all the time...I' $d$ want to be able to sort of pay respect to all of those who sort of helped me until that moment and so if I had to do it in a way that wouldn't let me then I think that would be one of the few times where I'd be hesitant to accept any offers to get there.

Stemming from his desire to 'pay respects' to those involved in his career, Richard said that PEDs are out of the question for him. Based on his evaluation, using them would mean disrespecting important people in his life. What is more, this desire is potentially the only thing stopping Richard from accepting offers to 'get there'. Thus, removing it would likely place him at greater risk for doping. Substantiating this, Steve suggested, "I couldn't look at my friends and family in the face if I was doing that". Likewise, Lucy admitted, "my family would be horrified if I ever did anything like that...my mum doesn't even like it when girls make comments about losing weight for running I mean the thought of taking something... she couldn't stand it". Crucially, these participants assume that their parents (and significant others) would not approve of them using PEDs; thus, deterring them from the possibility. 


\section{DOPING IN SPORT: DO PARENTS MATTER?}

\section{Discussion}

Substantiating and extending previous literature (e.g., Dimeo et al., 2012), our findings demonstrate that indeed, significant others (i.e., parents) play an important role in influencing student-athletes' likelihood to use banned substances in sport. Within our sample, participants appear to have developed a resistance to such behavior as a result (in part at least) of their parents' influence. Thus, our findings shed light on how the parent-athlete relationship can influence the development of athletes' values, beliefs and philosophies over their careers (see Bloodworth \& McNamee, 2010) and reiterate the importance of monitoring ASP (e.g., parents) and the attitudes and values they hold and transmit.

Based on our findings, parents become significant from an athlete's earliest days, either directly or indirectly establishing their initial sense of right and wrong. If this is the case, then identifying how a particular moral position is adopted and incorporated into an athlete's life after leaving the family home may be useful for informing anti-doping interventions and efforts moving forward. Illustrating the importance of this, within our sample it seems Mark had not completely internalized the personal beliefs promoted by his mum, and as a result, without her supervision he felt less inclined to remain accountable to them. Alternatively, it may be that Mark did internalize these personal beliefs; however, the situational temptation outweighs his moral compass. Either way, the potential influence of parents for establishing personal beliefs, and the significance of this within the context of sport doping, warrants further exploration. As demonstrated, removing the accountability of parents may lead university student-athletes to explore things that were previously off limits. This presents a potentially risky scenario and warrants consideration, especially by university athletic departments and anti-doping organizations.

With that in mind, it is important to consider Mazanov, Backhouse, Connor, Hemphill and Quirk's (2014) finding that among athlete support networks, family and friends 


\section{DOPING IN SPORT: DO PARENTS MATTER?}

possessed the least amount of doping knowledge. Thus, they call for greater engagement with parents in anti-doping efforts, suggesting that doping education needs to be directly targeted at them. Regardless of services offered though, if parents do not buy into the importance of drug-free sport or do not feel it is relevant to them, then ultimately their knowledge is futile (Backhouse \& McKenna, 2011). Therefore, anti-doping policy makers and researchers are tasked with helping parents recognize (and accept) their role in shaping athletes' attitudes, experiences and behaviors towards doping in sport. Notably, our findings offer initial evidence to this regard and should serve as a foundation for future research and anti-doping efforts to build upon. As a starting point, future research should explore the role of parents in shaping athletes' attitudes and values from the perspective of the parent and the athlete, gathering their personal accounts and reflections. Next, the evidence gathered should be integrated into anti-doping education and efforts. This approach has the potential to develop and shape education interventions that are personally meaningful to athletes and parents alike, increasing the likelihood of them engaging with the programs.

Offering further insights, Laure, Lecerf, Friser and Binsinger (2004) noted that among PED users and non-users, PED-using athletes presented with sharply degraded relationships with their parents compared to non-users. Various sanctioned professional athletes including Lance Armstrong (Macur, 2014) and Dwain Chambers (Chambers, 2009) - have also detailed degraded and/or non-existent relationships with a parent. In contrast, within our non-user athlete population, participants described predominantly personal relationships with their parents. Our findings support research (Erickson et al., 2015; Laure, Lecerf, Friser \& Binsinger, 2004) indicating that maintaining a close connection with at least one pro-social adult deters PED use among athletes. Further exploration of this possibility is warranted. For instance, it would be useful to determine if there are specific ages/stages in an athlete's life when parents are particularly important for protection. Also, research should seek to 


\section{DOPING IN SPORT: DO PARENTS MATTER?}

determine if the 'pro-social adult' has to be a parent, or could it be any adult meeting this criterion?

Given the apparent influence of parents in the context of athletes' attitudes, experiences and behaviors towards doping in sport, anti-doping organizations and efforts could capitalize on parents as a vessel for transmitting doping knowledge to athletes. Considering the level of trust and respect athletes attributed towards their parents, rather than relying primarily on strangers (e.g., educators, anti-doping organization representatives, etc.) to deliver anti-doping information to athletes, might it be possible to include parents in such endeavors? By providing parents with education about doping (i.e., facts, risks, warning signs, etc.), there is potential for: 1) them to (increasingly) recognize their role in anti-doping efforts, and 2) deliver (informal) anti-doping interventions/education directly to athletes. Cumulatively, this approach has the potential to enhance the (limited) impact of current antidoping efforts. Such an approach essentially constitutes 'educating the educator' and has the potential to increase athletes' engagement with anti-doping education while simultaneously increasing parents' recognition for the significant role they (can) play in deterring athletes from using banned substances.

As with all research, our findings need to be interpreted in light of innate research limitations. First, snowball sampling was employed, which may have led to an overly alike population (Pappa \& Kennedy, 2012). Yet, this strategy was deemed necessary due to the inherent challenges associated with recruiting participants for discussions around a taboo topic. To combat this, participants were encouraged to identify student-athletes beyond their personal teams and training groups in an attempt to encompass a wide-range of environments and support networks within the sample. Secondly, there is a risk with any research in this sensitive area that participants misrepresent or even lie about their PED use. As mentioned, the interview approach utilized in this research prioritized researcher-participant relationships 


\section{DOPING IN SPORT: DO PARENTS MATTER?}

characterized by mutual trust and rapport, thereby reducing the likelihood of dishonest responses (Douglas \& Carless, 2015). However, this does not eliminate the reality that athletes holding a counter-cultural view (e.g., thinking banned substance use in sport is acceptable) may have been resistant to (a) volunteer to participate in this research, and/or (b) unwilling to share their view during the interview. As such, it is important that we acknowledge this possibility. Third, participants in this study were student-athletes drawn from British universities. We do not wish to imply that their experiences are representative of all student-athletes. Finally, it is important to acknowledge that none of the participants in the sample had ever personally used PEDs. Still, multiple participants reported using various supplements, many acknowledged that future hypothetical situations could potentially compromise their firm stance against PEDs, and one individual suggested that he would be willing to use them now if he had access. In this context, the experiences have provided valuable insights regarding the influence of parents on student-athletes' attitudes, experiences and behaviors towards doping in sport.

\section{Conclusion}

The purpose of this research was to inform the psychology of doping in sport by qualitatively exploring British track and field student-athletes' attitudes, experiences and behaviors towards doping in sport while simultaneously exploring the (potential) influence of significant others in this context. By considering the participants' broader athletic experiences, this study has demonstrated that attachments to parents generally support(ed) the athletes in the pursuit of their goals and athletic careers. Furthermore, the influence of parents has remained constant and significant across the duration of participants' careers; thus, establishing their enduring impact. Parents appear to play a key role in forming and shaping athletes' personal morals which, in turn, have implications for their approach towards doping 


\section{DOPING IN SPORT: DO PARENTS MATTER?}

in sport. Contributing to this, participants generally assumed that their parents would not approve of them using PEDs. Consequently, they are deterred from doping. In light of the findings presented here, anti-doping policy makers and researchers are posed with the task of directly engaging with parents in the pursuit of drug-free sport. The first hurdle in this endeavor is convincing parents that they have an important role to play in this context. To achieve this, parents should be equipped with information on doping in sport and empowered (and utilized) to transmit this information directly to athletes. Importantly, considering the consistent presence of parents in these athletes' lives, this should be an on-going process rather than a one-off. 


\section{DOPING IN SPORT: DO PARENTS MATTER?}

\section{References}

Alaranta, A., Alaranta, H., Holmila, J., Palmu, P., Pietilä, K., \& Helenius, I. (2006). Selfreported attitudes of elite at hletes towards doping: differences between type of sport. International journal of sports medicine, 27(10), 842.

Aquilina, D. (2013). A Study of the Relationship Between Elite Athletes' Educational Development and Sporting Performance. The International Journal of the History of Sport, 30(4), 374-392. doi:10.1080/09523367.2013.765723

Backhouse, S. H., \& McKenna, J. (2011). Doping in sport: A review of medical practitioners' knowledge, attitudes and beliefs. International Journal of Drug Policy, 22(3), 198-202. doi:10.1016/j.drugpo.2011.03.002

Backhouse, S. H., Whitaker, L., Patterson, L., Erickson, K., \& McKenna, J. (2015). Social Psychology of Doping in Sport: A Mixed Narrative Synthesis.

Blank, C., Leichtfried, V., Schaiter, R., Furhapter, C., Muller, D., \& Schobersberger, W. (2013). Doping in sports: Knowledge and attitudes among parents of Austrian junior athletes. Scand J Med Sci Sports, 27(10), 12168.

Bloodworth, A. J., Petróczi, A., Bailey, R., Pearce, G. \& McNamee, M. J. (2012). Doping and supplementation: The attitudes of talented young athletes. Scandinavian Journal of Medicine \& Science in Sports, 22(2), 293-301.

Bloodworth, A., \& McNamee, M. (2010). Clean Olympians? Doping and anti-doping: The views of talented young British athletes. International Journal of Drug Policy, 21(4), 276-282. doi:10.1016/j.drugpo.2009.11.009

Bowlby, J. (1969). Attachment and loss, Vol. 1: Attachment. New York: Basic Books.

Bowlby, J. (1977). The Making and Breaking of Affectional Bonds. British Journal of Psychiatry, 130, 201-210. 


\section{DOPING IN SPORT: DO PARENTS MATTER?}

Braun, V., \& Clarke, V. (2006). Using thematic analysis in psychology. Qualitative Research in Psychology, 3(2), 77-101. doi:10.1191/1478088706qp063oa

Brown, C. H., Jr. (2001). Clinical cross-training: Compatibility of sport and family systems psychology. Professional Psychology: Research and Practice, 32(1), 19-26. doi:10.1037/0735-7028.32.1.19

Buckman, J. F., Farris, S. G., \& Yusko, D. A. (2013). A national study of substance use behaviors among NCAA male athletes who use banned performance enhancing substances. Drug and Alcohol Dependence, 131(1-2), 50-55.

doi:http://dx.doi.org/10.1016/j.drugalcdep.2013.04.023

BUCS. (2016). About Us. Retrieved from:

http://www.bucs.org.uk/page.asp?section=16983\&sectionTitle=About+Us

Carless, D., \& Douglas, K. (2013). "In the boat" but "selling myself short": Stories, narratives, and identity development in elite sport. The Sport Psychologist, 27(1), 27-39. doi:10.1123/tsp.27.1.27

Chambers, D. (2009). Race Against Me: My Story: Libros International.

Chan, D. K. C., Hardcastle, S. J., Lentillon-Kaestner, V., Donovan, R. J., Dimmock, J. A., \& Hagger, M. S. (2014). Athletes' beliefs about and attitudes towards taking banned performance-enhancing substances: A qualitative study. Sport, Exercise, and Performance Psychology, 3(4), 241-257. doi:10.1037/spy0000019

Collins, D., MacNamara, A., Collins, R., \& Bailey, R. (2012). Why Athletes say No to Doping? Examining the reasons underpinning athletes' decision not to dope. Retrieved from Montreal, CA: https://wada-main-prod.s3.amazonaws.com/resources/files/collinsfinal-2012-en_0.pdf

Dimeo, P., Allen, J., Taylor, J., Dixon, S., \& Robinson, L. (2012). Team dynamics and doping in sport: A risk or a protective factor? Retrieved from WADA: http://www.wada- 


\section{DOPING IN SPORT: DO PARENTS MATTER?}

ama.org/Documents/Education_Awareness/SocialScienceResearch/Funded_Research_Pr ojects/Dimeo_Team_Dynamics_2011_Report_EN.pdf

Donohue, B., Miller, A., Crammer, L., Cross, C., \& Covassin, T. (2007). A Standardized Method of Assessing Sport Specific Problems in the Relationships of Athletes with Their Coaches, Teammates, Family, and Peers. Journal of Sport Behavior, 30(4), 375-397.

Douglas, K., \& Carless, D. (2006). Performance Environment Research. UK Sport.

Douglas, K., \& Carless, D. (2009). Abandoning The Performance Narrative: Two Women's Stories of Transition from Professional Sport. Journal of Applied Sport Psychology, 21(2), 213-230. doi: http://dx.doi.org/10.1080/10413200902795109

Douglas, K. \& Carless, D. (2015). Life story research in sport: Understanding the experiences of elite and professional athletes through narrative. Abingdon: Routledge.

Dubin, C. (1990). Commission of Inquiry into the Use of Drugs and Banned Practices Intended to Increase Athletic Performance. Ottawa: Canadian Government Publishing Centre.

Dunn, M., \& Thomas, J. O. (2012). A risk profile of elite Australian athletes who use illicit drugs. Addictive Behaviors, 37(1), 144-147. doi: http://dx.doi.org/10.1016/j.addbeh.2011.09.008

Engelberg, T., Moston, S., \& Skinner, J. (2015). The final frontier of anti-doping: A study of athletes who have committed doping violations. Sport Management Review, 18(2), 268279. doi:http://dx.doi.org/10.1016/j.smr.2014.06.005

Erickson, K., McKenna, J. \& Backhouse, S. H., (2015). A Qualitative Analysis of the Factors That Protect Against Doping in Sport. Psychology of Sport \& Exercise, 16(2), 149-155. doi: $\underline{\text { http://dx.doi.org/10.1016/j.psychsport.2014.03.007 }}$

Fereday, J., \& Muir-Cochrane, E. (2006). Demonstrating Rigor Using Thematic Analysis: A Hybrid Approach of Inductive and Deductive Coding and Theme Development. 


\section{DOPING IN SPORT: DO PARENTS MATTER?}

International Journal of Qualitative Methods, 5(1), 1-11. Retrieved from http://ezproxy.leedsbeckett.ac.uk/login?url=http://search.ebscohost.com/login.aspx?direct $=$ true $\& \mathrm{db}=\mathrm{a} 9 \mathrm{~h} \& \mathrm{AN}=21331309 \&$ site $=$ eds-live $\&$ scope $=$ site

Fergusson, D. M., Vitaro, F., Wanner, B., \& Brendgen, M. (2007). Protective and compensatory factors mitigating the influence of deviant friends on delinquent behaviours during early adolescence. Journal of Adolescence, 30(1), 33-50. doi:http://dx.doi.org/10.1016/j.adolescence.2005.05.007

Field, T., Diego, M., \& Sanders, C. (2002). Adolescents' parent and peer relationships. Adolescence, 37(145), 121. Retrieved from http://search.ebscohost.com/login.aspx?direct=true $\& \mathrm{db}=\mathrm{s} 3 \mathrm{~h} \& \mathrm{AN}=6639800 \&$ site $=$ ehost$\underline{\text { live } \& \text { scope }=\text { site }}$

Fink, A. 1995. How to Sample in Surveys, London, SAGE.

Frank, A. W. (1995). The wounded storyteller. Chicago, IL: University of Chicago Press. Hair, E. C., Moore, K. A., Garrett, S. B., Ling, T., \& Cleveland, K. (2008). The Continued Importance of Quality Parent-Adolescent Relationships During Late Adolescence. Journal of Research on Adolescence, 18(1), 187-200. doi:10.1111/j.15327795.2008.00556.x

Hoff, D. (2012). Doping, risk and abuse: An interview study of elite athletes with a history of steroid use. Performance Enhancement \& Health, 1(2), 61-65. doi:http://dx.doi.org/10.1016/j.peh.2012.09.001

Johnson, M. B., Sacks, D. N., \& Edmonds, W. A. (2010). Counseling Athletes Who Use Performance-Enhancing Drugs: A New Conceptual Framework Linked to Clinical Practice. Journal of Social, Behavioral \& Health Sciences, 4(1), 1-14. doi:10.5590/jsbhs.2010.04.1.01 


\section{DOPING IN SPORT: DO PARENTS MATTER?}

Kindlundh, A., Isacson, D., Berglund, L., \& Nyberg, F. (1999). Factors associated with adolescent use of doping agents: anabolic-androgenic steroids. Addiction, 94, 543 - 553.

Laure, P., \& Binsinger, C. (2005). Adolescent athletes and the demand and supply of drugs to improve their performance. Journal of Sports Science and Medicine, 4, 272-277.

Laure, P., Lecerf, T., Friser, A., \& Binsinger, C. (2004). Drugs, Recreational Drug Use and Attitudes Towards Doping of High School Athletes. International journal of sports medicine, 25(2), 133-138. Retrieved from http://articles.sirc.ca/search.cfm?id=S-971313

Lenskyi, H. (2003). Out on the field: gender, sport and sexualities. Toronto: Women's Press.

Lucidi, F., Zelli, A., Mallia, L., Grano, C., Russo, P. M., \& Violani, C. (2008). The socialcognitive mechanisms regulating adolescents' use of doping substances. Journal of Sports Sciences, 26(5), 447-456. doi: 10.1080/02640410701579370

Macur, J. (2014). Cycle of Lies: The Fall of Lance Armstrong: HarperCollins.

Madigan, D. J., Stoeber, J., \& Passfield, L. (2016). Perfectionism and attitudes towards doping in junior athletes. Journal of Sports Sciences, 34(8), 700-706.

doi:10.1080/02640414.2015.1068441

Mazanov, J., Hemphill, D., Connor, J., Quirk, F. \& Backhouse, S.H. (2015). Australian athlete support personnel lived experience of anti-doping. Sport Management Review, 18, 218-230. doi: 10.1016/j.smr.2014.05.007

Mazanov, J., Backhouse, S., Connor, J., Hemphill, D., \& Quirk, F. (2014). Athlete support personnel and anti-doping: Knowledge, attitudes, and ethical stance. Scandinavian Journal of Medicine \& Science in Sports, n/a-n/a. doi:10.1111/sms.12084

McNamee, M. J. (2012). Ethics in Public Policy Making: A Case of Human Enhancement. European Commission FP7 Science in Society: Swansea University. 


\section{DOPING IN SPORT: DO PARENTS MATTER?}

Mercken, L., Sleddens, E. F. C., de Vries, H., \& Steglich, C. E. G. (2013). Choosing adolescent smokers as friends: The role of parenting and parental smoking. Journal of Adolescence, 36(2), 383-392. doi:http://dx.doi.org/10.1016/j.adolescence.2012.12.004

Morente-Sánchez, J., Mateo-March, M., \& Zabala, M. (2013). Attitudes towards Doping and Related Experience in Spanish National Cycling Teams According to Different Olympic Disciplines. PLoS ONE, 8(8), e70999. doi:10.1371/journal.pone.0070999

Morse, J. M. (2012). Qualitative health research: Creating a new discipline. Walnut Creek, CA: Left Coast Press.

Ohl, F., Fincoeur, B., Lentillon-Kaestner, V., Defrance, J., \& Brissonneau, C. (2013). The socialization of young cyclists and the culture of doping. International Review for the Sociology of Sport. doi:10.1177/1012690213495534

Overbye, M., Elbe, A.-M., Knudsen, M. L., \& Pfister, G. (2015). Athletes' perceptions of anti-doping sanctions: the ban from sport versus social, financial and self-imposed sanctions. Sport in Society, 18(3), 364-384. doi:10.1080/17430437.2014.982539

Pappa, E., \& Kennedy, E. (2012). 'It was my thought...he made it a reality': Normalization and responsibility in athletes' accounts of performance-enhancing drug use. International Review for the Sociology of Sport, 1-18.

Phoenix, C., Smith, B., \& Sparkes, A. C. (2010). Narrative analysis in aging studies: A typology for consideration. Journal of Aging Studies, 24(1), 1-11. doi:http://dx.doi.org/10.1016/j.jaging.2008.06.003

Piko, B. F., \& Kovacs, E. (2010). Do parents and school matter? Protective factors for adolescent substance use. Addict Behav, 35(1), 53-56. doi:10.1016/j.addbeh.2009.08.004 Plummer, K. (2001). Documents of life 2. Thousand Oaks, CA: Sage. 


\section{DOPING IN SPORT: DO PARENTS MATTER?}

Rennie, C. E., \& Dolan, M. C. (2010). The significance of protective factors in the assessment of risk. Criminal Behaviour \& Mental Health, 20(1), 8-22. doi:10.1002/cbm.750

Resnick, M. D., Bearman, P. S., Blum, R., \& et al. (1997). Protecting adolescents from harm: Findings from the national longitudinal study on adolescent health. JAMA, 278(10), 823832. doi:10.1001/jama.1997.03550100049038

Smith, A. C. T., Stewart, B., Oliver-Bennetts, S., McDonald, S., Ingerson, L., Anderson, A., . . Graetz, F. (2010). Contextual influences and athlete attitudes to drugs in sport. Sport Management Review (Elsevier Science), 13(3), 181-197. Retrieved from http://search.ebscohost.com/login.aspx?direct=true $\& d b=s 3 h \& A N=51297114 \&$ site=ehost$\underline{\text { live } \& \text { scope }=\text { site }}$

Smith, B. (2010). Narrative inquiry: ongoing conversations and questions for sport and exercise psychology research. International Review of Sport and Exercise Psychology, 3(1), 87-107. doi: $\underline{10.1080 / 17509840903390937}$

Sparkes, A. C., \& Smith, B. (2014). Qualitative Research Methods in Sport, Exercise and Health: From process to product: Routledge.

Sparkes, A. C., \& Smith, B. (2009). Judging the quality of qualitative inquiry: Criteriology and relativism in action. Psychology of Sport and Exercise, 10(5), 491-497. doi:http://dx.doi.org/10.1016/j.psychsport.2009.02.006

Storm, L. K., Henriksen, K., Larsen, C. H., \& Christensen, M. K. (2014). Influential Relationships as Contexts of Learning and Becoming Elite: Athletes' Retrospective Interpretations. International Journal of Sports Science \& Coaching, 9(6), 1341-1356. doi: $10.1260 / 1747-9541.9 .6 .1341$

Stronski, S. M., Ireland, M., Michaud, P.-A., Narring, F., \& Resnick, M. D. (2000). Protective correlates of stages in adolescent substance use: A swiss national study. 


\section{DOPING IN SPORT: DO PARENTS MATTER?}

Journal of Adolescent Health, 26(6), 420-427. doi:http://dx.doi.org/10.1016/S1054$\underline{139 X(99) 00057-9}$

Thomas, J. O., Dunn, M., Swift, W., \& Burns, L. (2011). Illicit drug knowledge and information-seeking behaviours among elite athletes. Journal Of Science And Medicine In Sport / Sports Medicine Australia, 14(4), 278-282. doi:10.1016/j.jsams.2011.02.001

WADA. (2015). World Anti-Doping Code. Montreal, Quebec: WADA.

Yesalis, C. E. (2000). Anabolic Steroids in Sport and Exercise. Champaign, Illinois: Human Kinetics.

Yusko, D. A., Buckman, J. F., White, H. R., \& Pandina, R. J. (2008). Alcohol, tobacco, illicit drugs, and performance enhancers: a comparison of use by college student athletes and nonathletes. Journal of American College Health, 57(3), 281-289. doi:

$\underline{\text { 10.3200/JACH.57.3.281-290 }}$

Zelli, A., Mallia, L., \& Lucidi, F. (2010). The contribution of interpersonal appraisals to a social-cognitive analysis of adolescents' doping use. Psychology of Sport \& Exercise, 11(4), 304-311. Retrieved from

http://search.ebscohost.com/login.aspx $?$ direct=true $\& d b=s 3 h \& A N=50964651 \&$ site $=$ ehost$\underline{\text { live } \& \text { scope }=\text { site }}$

Zenic, N., Stipic, M., \& Sekulic, D. (2013). Religiousness as a Factor of Hesitation Against Doping Behavior in College-Age Athletes. Journal of Religion and Health, 52(2), 386396. doi:10.1007/s10943-011-9480-x 